\title{
Teaching Music Historical Literacy Using Video Clips
}

\section{Nancy November}

School of Music, University of Auckland, New Zealand

\begin{abstract}
Four professionally-created, student-presented, three- to five-minute videos were integrated into two undergraduate music history courses at the University of Auckland, to support the development of key historical literacy skills. These include crucial skills and understandings that music students need to master in their first two years: identifying different kinds of music scores; understanding the difference between primary and secondary sources for music historical topics; finding one's way around critical, "complete works" editions of music; and finding and assessing music-related literature on the Internet. The intervention led to marked improvements in student learning in each of the four areas.
\end{abstract}

Keywords: history pedagogy; student-based learning; music history; literacy; online learning; video clips. 


\section{Introduction}

Educators in historical disciplines at the tertiary level need to rethink how they enable all students to become critical beings. For instance, second-year music history students at the University of Auckland surveyed in 2012-2014 tended to view music history as established fact and had great difficulty posing complex, critical questions and constructing critical, evidence-based arguments about history. History teachers have given much attention to historical literacy in various disciplines, especially at the secondary level, but much of the research is devoted to "content-area literacy" (for example Broomhead, 2005; Shanahan \& Shanahan, 2008; Damico \& Baildon, 2011). Recent research targets and explores the role of secondary school research projects in motivating students to develop disciplinary expertise in history (for example Sheehan, Hunter \& Howson, 2013). However, it is not until tertiary level that learners usually first encounter sharply divided discourse communities in the various academic disciplines. Isolated studies touch on discrete aspects of information literacy in music history (Christensen, Conor, \& Ritter, 2018). But to date, no study has specifically addressed teaching and learning a set of basic historical literacy skills in undergraduate music history.

This project was to create and integrate video clips into the teaching of undergraduate music courses in order to support the development of key historical literacy skills for music students. These include crucial skills and understandings that music students need to master in their first two years:

- identifying different kinds of music scores;

- understanding the difference between primary and secondary sources for music historical topics;

- finding one’s way around a critical, “complete works” editions of music; and

- finding and assessing music-related literature on the Internet.

This project aimed to develop these four literacy skills by integrating into music history courses four professionally-created, student-presented, three- to five-minute video clips on each of these topics. We took this approach based on our previous research that demonstrates high levels of online usage and digital literacy, and an affinity for student-centred, studentcreated learning scenarios among recent music students (November, 2011; November \& Day, 2012). The key skills were chosen by identifying particular problems students have had in previous years in first- and second-year music history courses. 


\section{Background and motivation}

The integration of modern teaching and modern resources within academia has been met with some resistance over the last three decades. Fear of loss of traditional academic literacy has been a stumbling block for the progress, inclusiveness, and relevance of tertiary institutions in today's world. Recent research has found, though, that information literacy learning in particular can be greatly assisted through digital media such as online courses and instructional videos (Renon, Pychyl, \& Motz, 2008; Tewell, 2010; Wyant, 2013). Video has proven to be a particularly effective method of delivering course content, especially when specifically designed for that purpose (Martin \& Martin, 2015).

However, in the field of music history, there has been an especially slow shift in perceptions regarding the use of digital and online teaching techniques and resources. This is perhaps because until very recently many of the key research resources, including several important music reference works and archive catalogues, were only available in hard copy. First-hand inspection of rare and fragile manuscripts still remains an important research step for musicologists.

Teaching basic music history skills by means of videos provides a useful way forward. Not only can these videos engage students repeatedly, when and where they choose to watch them, but they also allow for a level of learning that is socially and generationally relevant. As well as delivering information, videos can play an important role in embedding that information: they help students to make sense of new ideas and to create connections between pre-existing schema and any new content being delivered. By combining traditional course content with new modes of delivery, educators are able to bridge the gap between traditional instruction and modern learning, thus promoting meaningful learning, and life-long learning skills (Karppinen, 2005).

\section{Method}

In designing the sequence of four videos we noted that only a handful of public online resources fulfil a function similar to that which we intend for ours, and none of these use students as presenters. We surveyed twenty-two videos relating to music historical literacy skills acquisition at the tertiary level. These ranged over nine topics, the most popular of which were plagiarism and referencing (two videos); using music research data bases (two videos); identifying and finding journal articles (three videos); and finding scores (ten videos). All are publicly available on YouTube. The videos are fairly homogenous in style, mostly using a voiceover narration to a PowerPoint-like presentation. They were largely produced using screenshots, and the presenter is a music librarian or scholar. A typical example is that from Schenectady Country Community College's Begley Library, entitled 
"Finding Music Scores". The video uses voiceover narration with walkthrough-style demonstrative slides (https://libguides.sunysccc.edu/begleylibrary).

For comparison we surveyed six of the numerous non-music-specific online videos, and found more engaging examples, using cartoon figures, video demonstrations, and even background music (for example, the Charles Sturt University "Quick Library FAQs": https://www.youtube.com/watch?v=Nfpu6DHkVQo).

Most of the video clips we surveyed were under five minutes long. Exceptions include comprehensive videos from the University of Denver Music Library on navigating collected critical score editions with New Grove Dictionary of Music and Musicians (https://www.youtube.com/watch?v=TZSKrf-ojf0\&t=20s), and on using music research databases (https://www.youtube.com/watch?v=n-Dclz9eres). Both are narrated, in the style of a lecture with demonstrative slides. Each is around thirty minutes long.

We sought to create resources that would be much more engaging that anything currently available publicly for students learning music historical literacy skills. We aimed to create resources that students would want to watch repeatedly, for learning and enjoyment. Our project drew in particular on the work of Cook et al. (Cook, Bingham, Reid, \& Wang, 2015; Cook, Reid, \& Wang, 2013), which shows that two- to three-minute, student-centred clips are the most effective type of online visual media for reaching target audiences of undergraduate learners. These researchers' experience suggested to us that we should embed the clips within appropriate supporting materials online, scaffolding their use appropriately within each course. We also drew on the work of Dreon, Kerper, \& Landis (2011), who describe digital storytelling as "the art of combining narrative with digital media such as images, sound, and video to create a short story” (5). Such short stories are an effective mode of communicating content to today's learners, who are familiar with the narrative modes prevalent in the media and popular culture today. Todays' students are often highly digitally literate. So teachers can make use of digital media to communicate course content effectively while promoting critical thinking about, and engagement with, the learning tasks.

We undertook a five-step process to create the videos: we sought ethics approval to carry out the project (since it involved some of our own students, and would potentially be released to the public); we auditioned to find suitable School of Music student and staff "talent" to act in the videos; we produced suitable scripts, in consultation with students and professionals in Media Productions at the University of Auckland; we shot the videos over a period of one week; and then we reviewed and edited the videos.

Each clip showcased music students' talents as presenters and performers; and in each one, two students engage in dialogue with each other and with music staff. Each clip tells those two students' story of exploration in relation to the given music historical literacy skill. 
In order to integrate the videos into courses, we designed appropriate supporting materials including written transcripts, practical examples, and links to related literature and other videos; we then embedded the clips within a specially designed assignment sequence in CourseBuilder, the University of Auckland's online learning platform: Hibbert (2014) has shown that instructional videos with high numbers of views are often those that are directly connected to course assignments or course assessments. We trialled the clips in a music course for advanced undergraduates, a history-based course entitled “The Symphony”, which was run in 2017 (see Figure 1). Then, in 2018, we used the clips in a second-year music history course entitled “Music, History, and Ideas”.

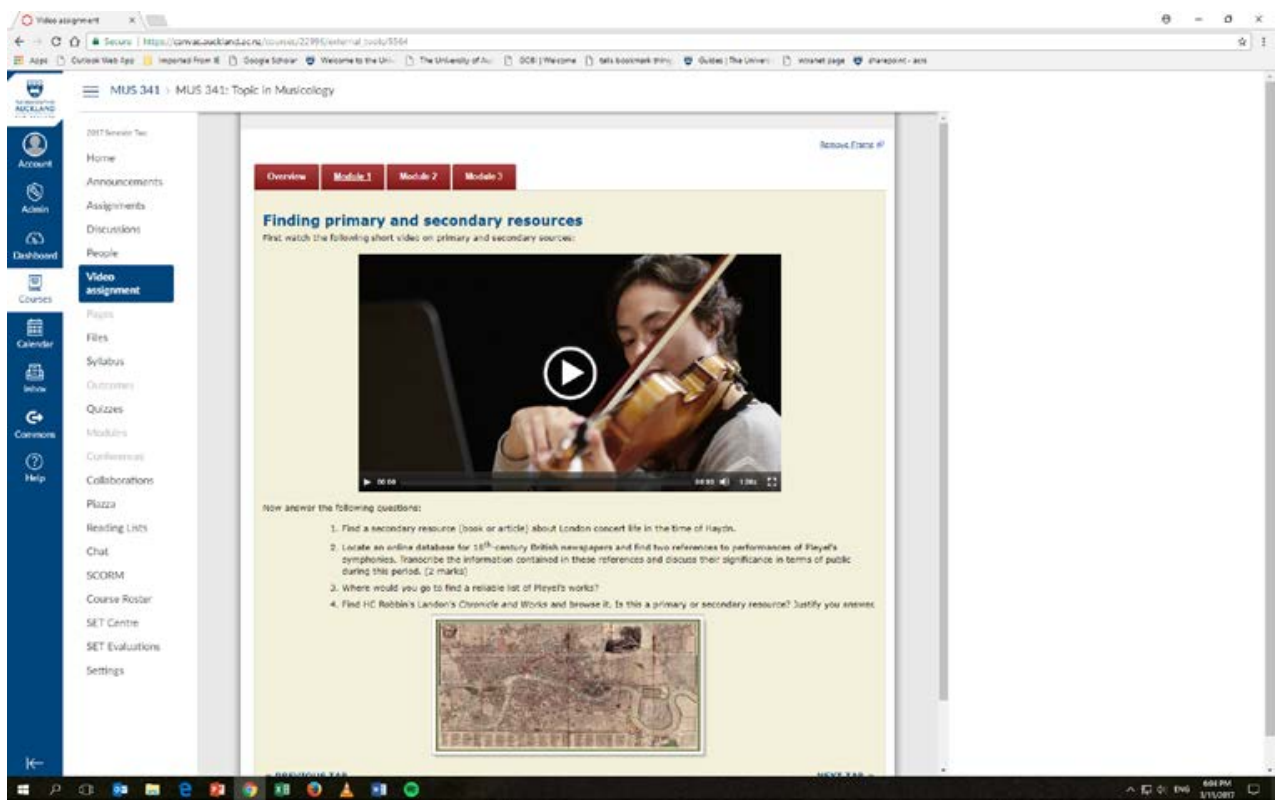

Figure 1. An example of a video clip embedded within the CourseBuilder website for "The Symphony"

\section{Results and conclusions}

After each course we carried out focus groups with students to help us to evaluate the videos and the CourseBuilder framework. In "Music, History, and Ideas" in 2018, we also carried out "before" and "after" surveys ( $\mathrm{n}=26$ and 24, respectively) to ascertain which tasks students perceive to be the most difficult in relation to music historical literacy learning, and which teaching strategies they found most helpful in accomplishing these tasks. The "before" surveys took the form of anonymous questionnaires in which the students were asked to define terms such as "critical edition”, "primary and secondary resource”, and asked how they would assess a given online resource. After the students had completed the online modules, in which they watched each video in turn and answered questions about each, they 
were once again assessed on their understanding in each of these areas. A further evaluative questionnaire, delivered at the end of the 2018 course, comprised a list of fifteen short-answer and open-ended questions. These were designed to show how students rated the videos in terms of various parameters: length, depth, use of humour, clarity of main message, helpful and unhelpful aspects, and so forth.

The most striking data were as follows:

Before the working with the videos

- $\quad 31 \%$ of students in the course had trouble knowing how to assess online resources for music history;

- 50\% of students could not define a "primary" or "secondary" resource for writing a music history essay;

- $\quad 92 \%$ of students could not define a "critical edition of music”;

- $100 \%$ of students could not name or briefly describe any other kinds of musical edition.

After the working with the videos

- $\quad 80 \%$ of students in could define a "primary" or "secondary” resource for writing a music history essay;

- $\quad 73 \%$ of students in could define and discuss a "critical edition of music”;

- $\quad 72 \%$ of students in could name and briefly describe other kinds of musical edition.

The project has as its central aim the development of students' historical literacy skills in an innovative way, building on their digital literacy skills. This aim is in line with the graduate attributes of critical thinking and global citizenship that are advocated in recent literature on historical literacy. Nokes (2011), for instance, has argued that the purpose of developing "historical literacy" is to produce students who are "able to negotiate and create the complex texts of the Information Age" (6). This project used video and online instruction to help achieve this aim effectively, efficiently, and accessibly, as follows:

\subsection{Effective e-learning}

Music students are among the highest users of online resources at the University of Auckland, and they show high levels of digital literacy. This situation is likely to be similar at other large, diverse tertiary institutions. The CourseBuilder environment in which the videos were embedded was designed to further develop students' digital literacy and foster independent thinking, especially through question prompts that were designed to test their learning from the videos, and to test whether they could apply the knowledge in relevant situations. 


\subsection{Efficient literacy learning and teaching}

Teaching music historical literacy skills has traditionally involved library tutorials and inclass library sessions. This involves specialist staff, and takes time away from the teaching and learning of other key concepts and course content. In the past, Music Library staff found that they were frequently approached by students with basic questions regarding these skills, especially as essay and assignment deadlines approached. In this project we created an online resource that students can revisit as often as they need.

\subsection{Accessible learning}

The video clips were developed in consultation with students, and in creating them we drew on student and teacher talent. In focus groups, students told us that they greatly appreciated seeing their peers on film and in familiar situations. The feelings of familiarity and proximity helped them to see the relevance of the learning tasks and helped them to relate to the material. Students repeatedly commented that they enjoyed the element of humour in the videos, as well as the musical performances. Although these aspects were an aside from the main material, they helped greatly with engagement in and the enjoyment of what might otherwise have been perceived as dry or even irrelevant material.

But could a less resource-consuming means of delivering the same material lead to similar learning outcomes? Yes, quite possibly. In the questionnaire delivered at the end of "Music, History, and Ideas" in 2018, twenty-one out of the twenty-four survey respondents responded "yes" to the question: "Would you be happy to view less 'professional' videos if the topics and content were useful, e.g., student-created videos?” It was notable that five students qualified their responses to this question, one observing that the quality would need to be good, and four emphasising that the content would need to be relevant. The use of studentcreated videos for subject-specific literacy learning is a subject for future research.

\section{References}

Broomhead, P. (2005). (Re)Imagining Literacies for the Music Classroom. In R. J. Draper (Ed.), (Re)Imagining Content-Area Literacy Instruction (pp. 69-81). New York, NY: Teacher's College Press.

Cook, S. T., Reid, S., \& Wang, L. (2013). Speaking their language: a student-cantered approach to translating university policies into interactive practice. In A. Nayak, S. Saddiqui (Eds.), From Policy to Practice (pp. 139-153). Sydney, Australia. URL: https://researchspace.auckland.ac.nz/handle/2292/25275.

Cook, S., Bingham, T., Reid, S., \& Wang, L. (2015). Going “massive”: Learner engagement in a MOOC environment. Paper presented at THETA 2015 - Create, Connect, Consume - Innovating today for tomorrow, Gold Coast, Australia. 11-15 May 2015. URL: http://hdl.handle.net/2292/28183. 
Christensen, B., Conor, E., \& Ritter, M. (2018). Information Literacy in Music: An Instructor's Companion. Middleton, WI: A-R Editions.

Damico, J. S., \& M. Baildon, M. (2011). Content Literacy for the $21^{\text {st }}$ Century: Excavation, Elevation and Relational Cosmopolitanism in the Classroom. Journal of Adolescent \& Adult Literacy, 55(3), 232-243. doi:10.1002/JAAL.000028.

Dreon, O., Kerper, R. M., \& Landis, J. (2011). Digital Storytelling: A Tool for Teaching and Learning in the YouTube Generation. Middle School Journal, 42(5), 4-10. doi:10.1080/00940771.2011.11461777.

Hibbert, M. (2014). What Makes an Instructional Video Compelling. Educause Review, 4. Retrieved from: http://er.educause.edu/articles/2014/4/what-makes-an-onlineinstructional-video-compelling. doi: 10.7916/D8ST7NHP.

Karppinen, P. (2005). Meaningful Learning with Digital and Online Videos: Theoretical Perspectives. AACE Journal, 13(3), 233-250.

Martin, N. A., \& Martin, R. (2015). Would You Watch It? Creating Effective and Engaging Video Tutorials. Journal of Library \& Information Services in Distance Learning, 9(12), 40-56. doi:10.1080/1533290X.2014.946345.

Nokes, Jeffrey, (2011). Historical Literacy. Social Studies: Newsletter of the Utah State Office of Education.

November, N. R. (2011). Literacy Loops and Online Groups: Promoting Writing Skills in Large Undergraduate Music Classes. Journal of Music History Pedagogy, 2(1). Retrieved from: http://www.ams-net.org/ojs/index.php/jmhp/article/view/31.

November, N. R and Day, K. (2012). Using Undergraduates’ Digital Literacy Skills to Improve their Discipline-Specific Writing: A Dialogue. International Journal of the Scholarship of Teaching and Learning, 6(2). Retrieved from: http://academics.georgiasouthern.edu/ijsotl/v6n2/articles/PDFs/Acc\%20Art_November \%20\&\%20Day.pdf.

Renon, F., Pychyl, T. A., \& Motz, C. P. (2008). A Conversation about Collaboration: Using Web-based Video Streaming to Integrate Information Literacy into a Research Assignment for a Large Blended Class. In T. P. Mackey \& T. E. Jacobson (Eds.), Using Technology to Teach Information Literacy (pp. 29-50). New York, NY: USA: NealSchuman.

Shanahan, T. \& Shanahan, C. (2008). Teaching Disciplinary Literacy to Adolescents: Rethinking Content-Area Literacy. Harvard Educational Review, 78(1), 40-59. doi: 10.17763/haer.78.1.v62444321p602101

Sheehan, M., K. Hunter, K., \& Howson, J. (2013). “Thinking Historically”: The Role of NCEA Research Projects in Motivating History Students to Develop Disciplinary Expertise. Retrieved from: http://www.tlri.org.nz/tlri-research/researchcompleted/school-sector/\%E2\%80\%98thinking-historically\%E2\%80\%99-role- ncearesearch- projects.

Tewell, E. (2010). Video Tutorials in Academic Art Libraries: A Content Analysis and Review. Art Documentation: Journal of the Art Libraries Society of North America, 29(2), 53-61. Retrieved from: https://www.jstor.org/stable/27949554. doi: 10.1086/adx.29.2.27949554 
Wyant, N. (2013). The Effectiveness of Online Video tutorials as Supplemental Library Instruction. Kansas Library Association College and University Libraries Section Proceedings, 3(1), 39-43. doi:10.4148/culs.v1i0.1835. 